\title{
MECHANICAL CONNECTION OF METAL STRUCTURES IN WAGON BUILDINGS
}

\author{
Ramis Zaripov ${ }^{1}$, Pavels Gavrilovs ${ }^{2}$ \\ ${ }^{1}$ Toraighyrov University, Kazakhstan; ${ }^{2}$ Riga Technical University, Latvia \\ ramis.zaripov@mail.ru,pavels.gavrilovs@rtu.lv
}

\begin{abstract}
The article reflects information from the field of designing freight railwagons. The issue of assembling elements of a freight wagon body made of aluminum alloy without welding is considered. The results of testing pins with a crimp head are presented. Crimp head pins are used as an alternative to welding. Such connections have the advantages of both rivet and bolt connections. They eliminate the shortcomings of the bolted connection, in particular, the weakening of the bolt tension as a result of unscrewing the nut during vibration. For the correct choice of the number of connections, it is necessary to determine the load-bearing capacity of a single connection under different loads (static, cyclic, shock), taking into account the actual operating conditions of the connected body components. The proposed samples simulate the working conditions of individual body elements. Based on the test results of model samples, it is possible to determine the load-bearing capacity of pins with a crimp head of the selected type and calculate the number of connections that can withstand standard loads without destruction during the specified service life of the wagon. The tests have shown that the strain relief and loosening of the pins with the crimp head occur at different impact energies, depending on the amount of preload and the size of the connection parts. In the tests of joints with samples of aluminum profile it was found that proper selection of the type of pins and crimping heads, as well as the number of joints of individual elements of the freight wagon body of aluminum alloy ensure long-term usage of the body without damaging the base metal and the joints. The tests have shown that unloading from interference and weakening of the $\mathrm{PwCH}$ connection occurs at different impact energies, depending on the amount of preload and the dimensions of the details of the $\mathrm{PwCH}$ connection: $\mathrm{PwCH}$ connections with a crimping head with an internal diameter of $16.6 \mathrm{~mm}-1.25 \mathrm{~kJ}$ (total with an interference fit of $500 \mathrm{MPa}$ ); $\mathrm{PwCH}$ connection with a crimping head with an internal diameter of $17.0 \mathrm{~mm}-0.15-0.25 \mathrm{~kJ}$; PwCH connection with a crimping head with an inner diameter of $16.65 \mathrm{~mm}-1.5-2.0 \mathrm{~kJ}$.
\end{abstract}

Keywords: welding, wagon, mechanical connection, pin with crimp head, impact resistance, testing.

\section{Introduction}

The use of aluminium alloys in the design of freight wagons is the most perspective direction in the wagon building industry. This is due, firstly, to the opportunity to significantly reduce the weight of wagons and enhancing their capacity and, secondly, with the lowering of the cost of repairing the wagons due to high corrosion and abrasion resistance of aluminum alloys of the individual brands.

Currently, the main technological process in the assembly of wagons is welding. In construction, in factory manufacturing, more than $95 \%$ of steel structures are made by welding. During installation, the level of application of welding is about $60 \%$.

Widespread welding is due to the possibility of mechanization and automation of work. As a result of introduction of welding, the laboriousness of manufacturing some structures compared to rivets decreased by more than $20 \%$, while reducing steel consumption by $10-15 \%$ (replacing lap joints with butt joints) [1].

Along with the obvious technological advantages, the use of welding entails some negative features. These include: increased stress concentration due to the presence of defects in the seams (undercuts, lack of penetration, pores, slag inclusions); mechanical heterogeneity of welds; residual stresses; possible deviations of structural elements from the design form caused by welding deformations. These shortcomings, especially their combination, can affect the performance of welded structures under static and cyclic loading, being the causes of brittle and fatigue fractures.

In other industries, for example, in aviation, welding due to these shortcomings is used less often than in construction. In wagon building, welding is the main technological process for assembling wagon bodies and frames. However, rivet and bolt connections are present in frame designs.

Mainly at the junction of thick-walled elements, access to which is difficult (emphasis automatic couplings, hinges).

The last 20 years in foreign wagon building industry there has been an increase in the interest in bolt and rivet joints in connection with the emergence of a new type of joints - "pin with crimp head" Huck-Fit and Huck-Spin (PwCH joints), Fig. 1. 


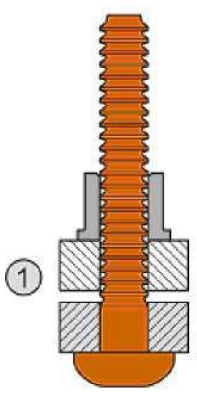

(2)

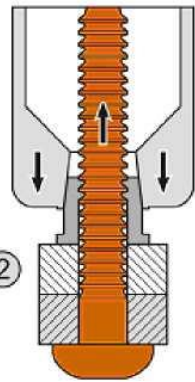

(3)

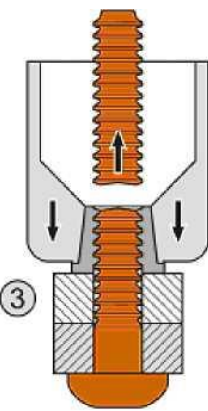

(4)

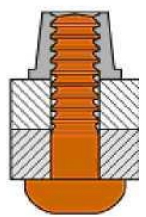

Fig. 1. Scheme of formation of the PwCH connection with separation of the shank:

1 - installation of the pin and crimp head in the holes of the connected plates; 2 - shank preload and head crimping; 3 - completion of crimping the head and separation of the shank;

4 - finished (PwCH connection)

$\mathrm{PwCH}$ joints have the advantages of both riveted and bolted joints. They eliminate the disadvantages of the bolted connection, in particular, the weakening of the tightness of the bolt as a result of unscrewing the nut during vibration.

There is an increase in the volume of connections made on wagons using the technology (PwCH connection). Thus, the assembly of gondola wagons with a body of aluminum alloys at Johnstown America enterprises is carried out using $\mathrm{PwCH}$ joints in the complete absence of welding.

$\mathrm{PwCH}$ joints have a number of advantages compared to welding, riveted and bolted joints. In the CIS, this technology is so far only used in aircraft manufacturing [2,7].

Tests of PwCH connections were carried out in order to determine certification parameters and areas of rational use of this type of compounds in the design of the frame and body of freight wagons.

\section{Materials and methods}

During the tests, the calculated characteristics of the $\mathrm{PwCH}$ connection were determined: resistance to shear, separation of the head, crushing, weakening of the interference fit under shock load, etc.

To determine the bearing capacity of the $\mathrm{PwCH}$ compounds under cyclic loading, the tests were carried out on 2 types of samples shown in Fig. 2.

$a$

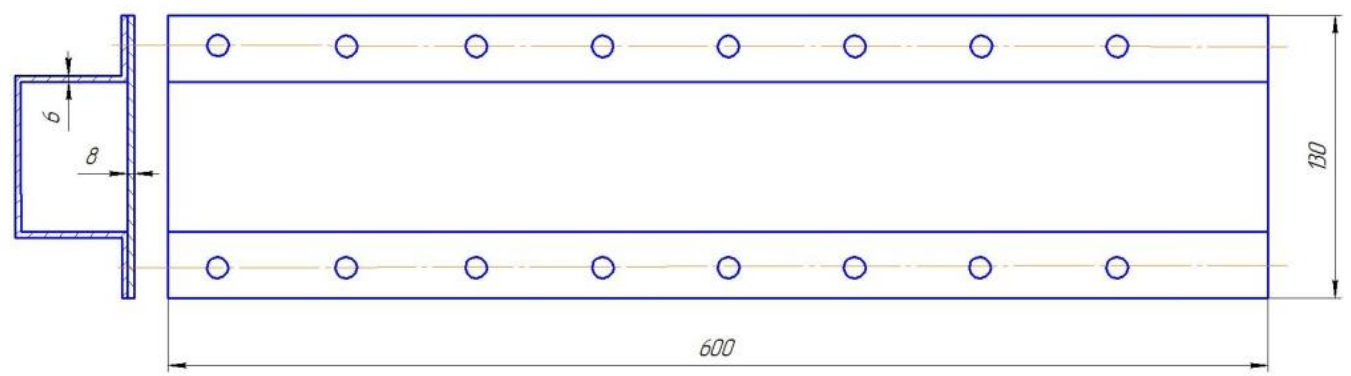

$b$

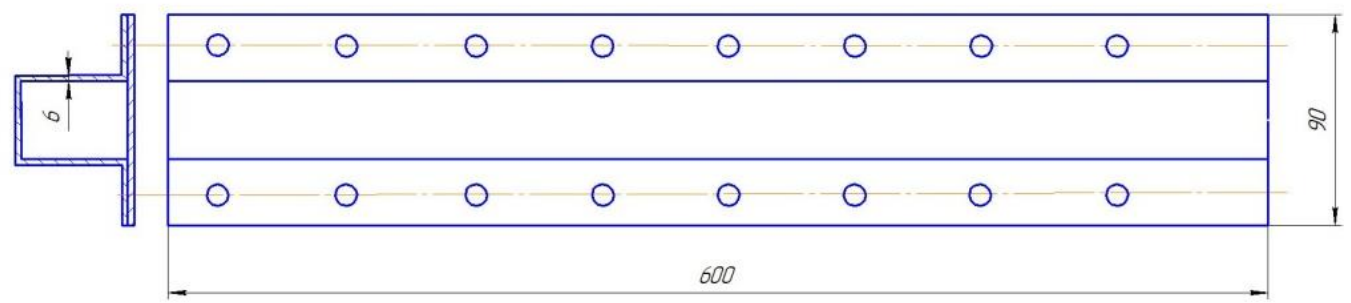

Fig. 2. Samples for determining the bearing capacity of $\mathrm{PwCH}$ compounds 
Fatigue tests of type 1 samples were carried out on a TsDM-100 hydraulic pulsator with a loading frequency of $5 \mathrm{~Hz}$ and a cycle asymmetry coefficient of $r=0.1$, the test base was $2 \times 106$ cycles. Samples with a length of $600 \mathrm{~mm}$ were placed on the supports of the hydropulsator with the profile up. The distance between the supports is $500 \mathrm{~mm}$. A load was applied in the middle between the supports through a steel gasket so as not to cause local deformation and fracture under the punch (Fig. 3). The number of cycles to failure (the appearance of cracks measuring $6 \mathrm{~cm}$ or more) was determined.
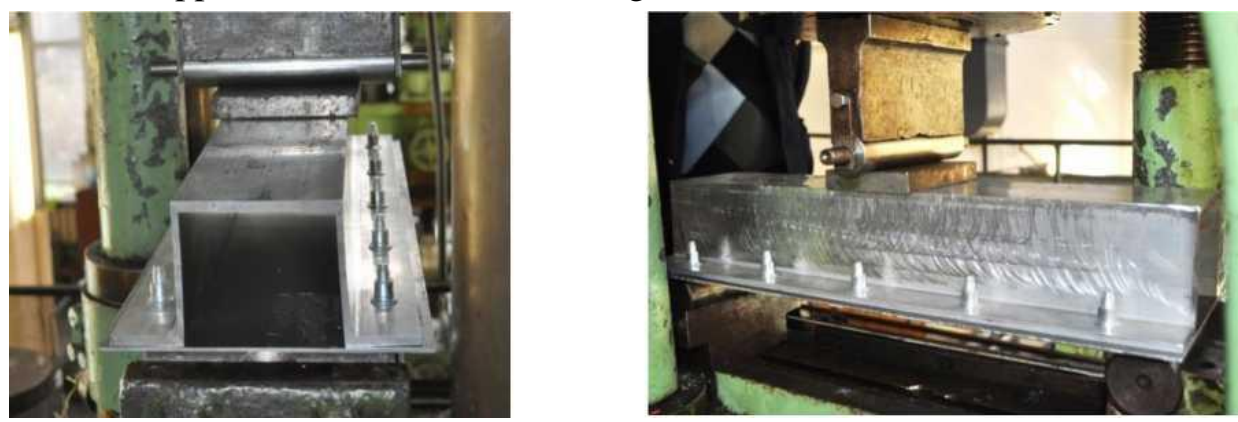

Fig. 3. General view of the 5th type specimen on supports of the testing machine TsDM-100

Fatigue test results are shown in Table 1 and Figure 4.

Table 1

Results of fatigue tests of samples of the 1-st type

\begin{tabular}{|c|c|c|c|c|}
\hline Sample No. & Load $\boldsymbol{P}_{\min }, \mathbf{k N}$ & Load $\boldsymbol{P}_{\mathbf{m a x}}, \mathbf{k N}$ & Number of cycles & Result \\
\hline $1-1$ & 100 & 10 & 835000 & Fracture \\
\hline $1-2$ & 90 & 9 & 694000 & Fracture \\
\hline $1-3$ & 80 & 8 & 1067000 & Fracture \\
\hline $1-4$ & 70 & 7 & 3150000 & Fracture \\
\hline
\end{tabular}

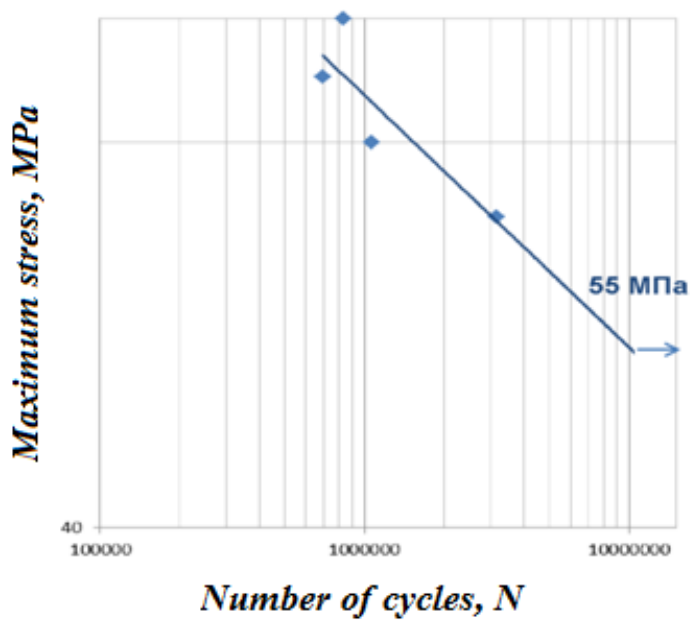

Fig. 4. Curve of limited durability of type 1 samples

The cross-sectional area of the Omega profile is large $-17.7 \mathrm{~cm}^{2}$, moment profile resistance $180 \mathrm{~cm}^{3}$. Stresses in the lower flanges of the profile with a load of $5 \mathrm{t}$ are $34.7 \mathrm{~N} \cdot \mathrm{mm}^{-2}$.

Almost all samples were destroyed by fatigue cracks in the area where the $\mathrm{PwCH}$ compound was placed (Fig. 5 a). Cracks developed in the pressed profile (omega - large) at an angle close to 450 relative to the axis of the sample.

A great influence on the fatigue resistance is exerted by the correctness of the profile, compliance with the straightness and perpendicularity of the profile shelves.

If the perpendicularity of the shelves of the profile is not observed, additional stresses arise in the profile and the zone of fracture onset shifts to the place where the shelves mate (Fig. 5, b, c). 

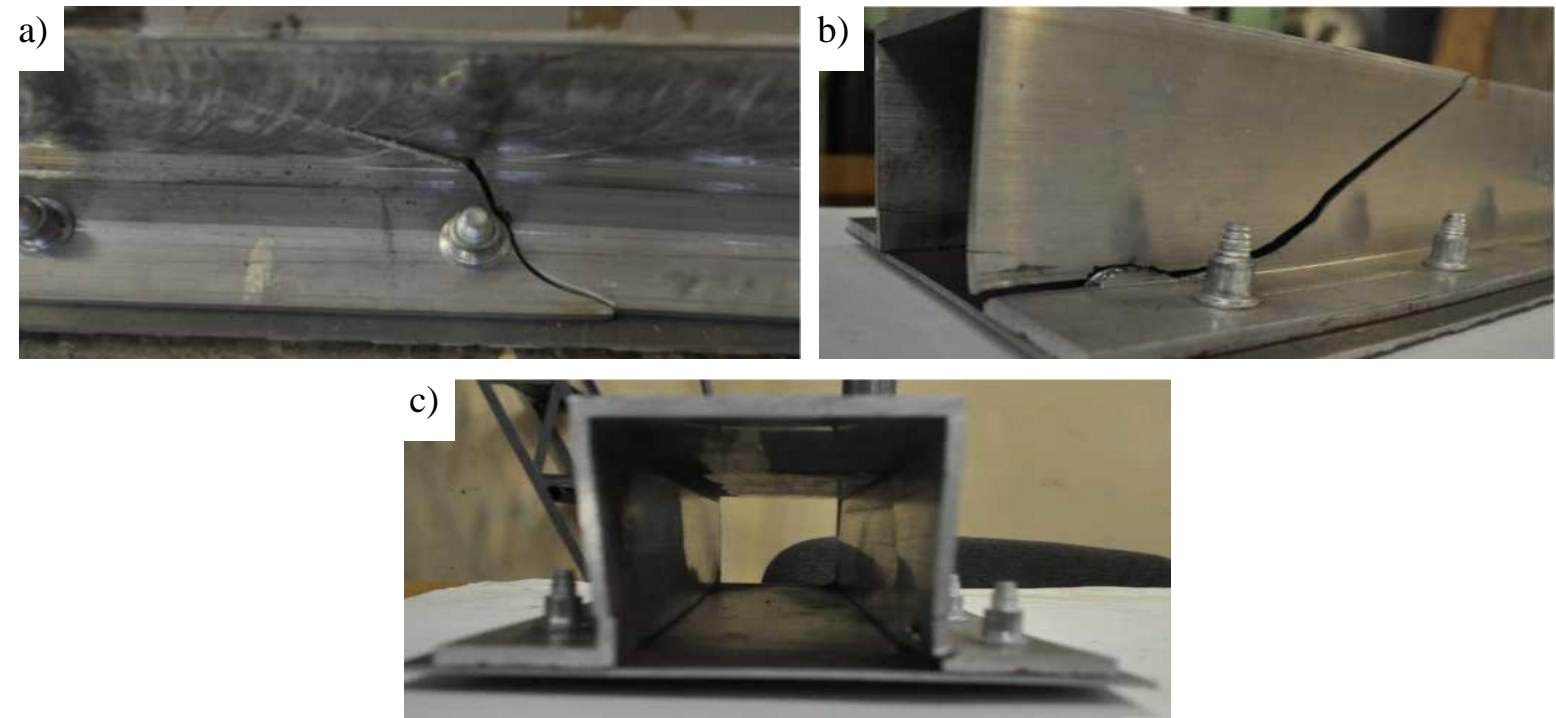

\section{Fig.5. Nature of destruction of composite samples of the 5th type when tested for fatigue resistance}

Earlier, when testing the $\mathrm{PwCH}$ connection "profile (omega large) $+3 \mathrm{~mm}$ sheet" for three-point bending with a distance between the supports of $0.5 \mathrm{~m}$ and the application of a cyclic load in the middle of the span, the limited endurance limit was $50 \mathrm{kN}$ (load) or $34,7 \mathrm{~N} / \mathrm{mm}^{2}$ voltage. However, the nature of the fracture of the specimens (the development of cracks from the end face of the Omega Big profile or directly at the support) cast doubt on the reliability of determining the maximum bending stresses that the specimen can withstand without fracture. Samples $600 \mathrm{~mm}$ long with a distance between supports of $500 \mathrm{~mm}$ and a profile and sheet height of $103 \mathrm{~mm}$ do not meet the requirements of the Saint-Venant rule ("half the distance between supports should be no less than 3 times the height of the sample").

In order to exclude the Saint-Venant factor and incorrectness in determining the endurance limit of samples No. 6 during cyclic bending, two samples were made with a length of $1200 \mathrm{~mm}$. On the first sample, the Omega Big profile was fastened to a $3 \mathrm{~mm}$ thick sheet using the BobTail PwCH connection with a tension tip, Fig. 6. Pin - BT-BR12-6GA, crimp head BTC5-R12GAH, pin diameter $9.5 \mathrm{~mm}$, thickness range of connecting plates $6.35-12.7 \mathrm{~mm}$, tensile force $26.6 \mathrm{kN}$.
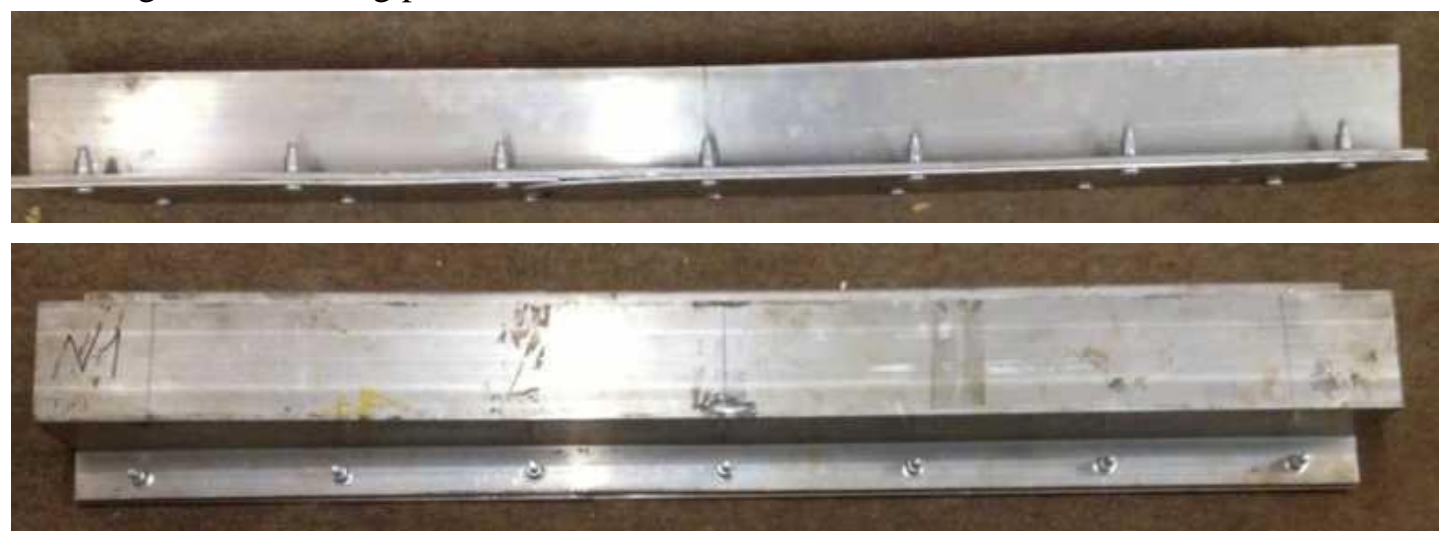

Fig. 6. General view of the sample with the PwCH connection of the type "BobTail"

In the second sample, for connecting the omega large profile with a sheet $3 \mathrm{~mm}$ thick, the $\mathrm{PwCH}$ connection was used with the same pin diameter of $9.5 \mathrm{~mm}$, but with a tear-off shank. For a more uniform pressure distribution, a $2 \mathrm{~mm}$ thick pad of $\mathrm{AMg} 6$ alloy was placed under the crimping head [3].

Both samples were tested for fatigue on a TsDM-100 pulsator according to a three-point bending scheme. The distance between the supports was $1000 \mathrm{~mm}$, a bending load was applied in the middle of the span between the supports, the loading frequency was $5 \mathrm{~Hz}$, the test base was 2 million cycles, the asymmetry coefficient of the cycle was $r=0.1$, Fig. 7 . 


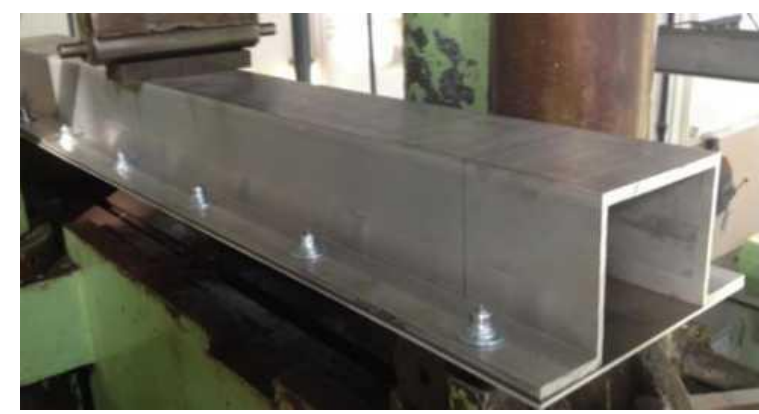

Fig. 7. Testing composite samples for pulsatile TsDM-100

The first sample at a load of $P_{\max }=30 \mathrm{kN}$ collapsed after 1,411,000 loading cycles. The nature of the destruction is shown in Fig. 8.

The destruction of the sample began from the edge of the profile, at about $45^{\circ}$ to the direction of load application, at a distance of $120 \mathrm{~mm}$ from the nearest $\mathrm{PwCH}$ connection and the plane of load application. A fatigue crack in the sheet arose at a distance of about $180 \mathrm{~mm}$ from the plane of application of the load, near 3 rows of $\mathrm{PwCH}$ joints from the edge of the sample [4].
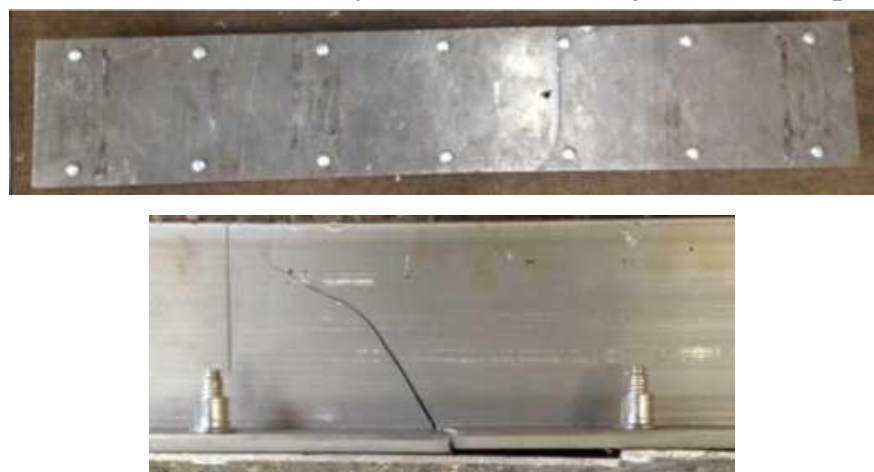

Fig. 8. Nature of fatigue failure of the first sample at three-point bend

The occurrence of an initial fatigue crack at the edge of the Omega Big profile could be affected by the presence of additional stresses in the joint due to the need to edit the profile to ensure parallelism of the side shelves [5].

The second sample withstood 2,000,000 cycles at $P_{\max }=30 \mathrm{kN}$ and was overloaded at $P_{\max }=40 \mathrm{kN}$. At a load of $P_{\max }=40 \mathrm{kN}$, the sample collapsed after 1174900 cycles. The fracture pattern, Fig. 9, differs from the fracture pattern of the first specimen: the initial fatigue crack appeared in the omega large profile near the $\mathrm{PwCH}$ joint and developed obliquely to the point of application of the bending load. The destruction of the sheet also began from 3 rows of $\mathrm{PwCH}$ compounds.

The increased load-bearing capacity of the second sample may be due to the absence of cold profile editing and the presence of a gasket that reduces the pressure of the head of the $\mathrm{PwCH}$ connection on the shelf of the Omega Big profile [6,11-14].

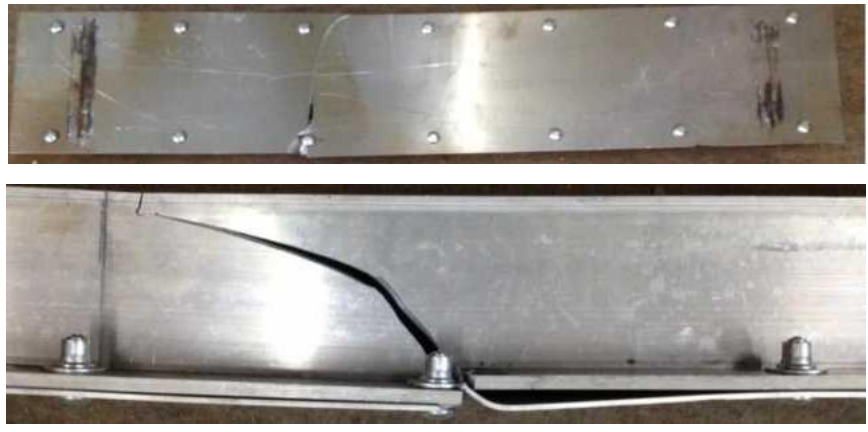

Fig. 9. Nature of destruction of the second sample (PwCH connection with a tear-off shank) during three-point cyclic bending 
The moment of resistance $(W)$ of the omega large profile is $180 \mathrm{~cm}^{3}$, the bending moment is $M=P L / 4$. For the first sample, the maximum cyclic bending stress, at which failure occurred after $1,411,000$ cycles, was $a_{\max }=\mathrm{M} \cdot \mathrm{W}^{-1}=[30000 \mathrm{x} 100 / 4] / 180=4166 \mathrm{~N} \cdot \mathrm{cm}^{-2}=41.6 \mathrm{~N} \cdot \mathrm{mm}^{-2}$.

The second sample failed after 1174900 cycles at maximum cyclic stresses $a_{\max }=\mathrm{M} \cdot \mathrm{W}^{-1}$ $=[40000 \times 100 / 4] / 180=5555 \mathrm{~N} \cdot \mathrm{cm}^{-2}=55.5 \mathrm{~N} \cdot \mathrm{mm}^{-2}$.

Thus, depending on the manufacturing technology of $\mathrm{PwCH}$ compounds, fatigue life of more than 1 million cycles is achieved at voltages not exceeding $41 \mathrm{~N} \cdot \mathrm{mm}^{-2}$ in the first and not more than $55 \mathrm{~N} \cdot \mathrm{mm}^{-2}$ in the second embodiment.

Pin tightness measurement during $\mathrm{PwCH}$ connection formation. The longitudinal stresses (strains) in the pin shaft were measured during the formation of the $\mathrm{PwCH}$ connection using special equipment recording digitally the elastic deformation of the pin shaft on a computer disk [8-11].

$\mathrm{PwCH}$-connections for measuring interference were made in plates with a slot or in plates with a groove under the overlay, Fig.10.

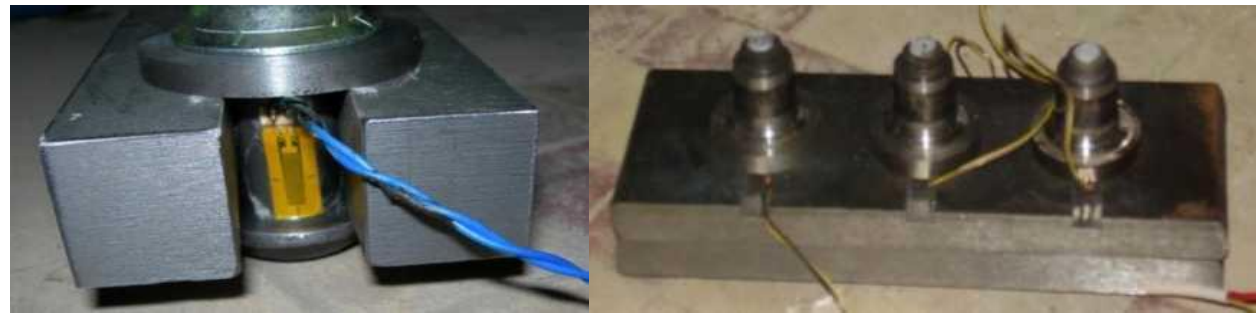

Fig. 10. Measurement of the tightness of the pin at the time of formation of the bar - connections

The main means of recording data in the tests was a multichannel PC-compatible measuring amplifier at the carrier frequency "Spider 8" company HBM (Germany). We used KF 5P1-10-20 A-12 strain gages with a base of $10 \mathrm{~mm}$ and a resistance of $200 \Omega$. For switching, KMM7x0.12 type cables with 2RM-18 connectors are used. Quantization frequency $200 \mathrm{~Hz}$ (without filters).

The change in stresses (deformations) of the pin shaft during the formation of the $\mathrm{PwCH}$ connection (Fig. 11) has several characteristic sections:

- pin tension (section 1),

- formation of the crimp head and transfer of pressure to the crimp head (section 2),

- separation of the shank (section 3)

- steady tightness of the $\mathrm{PwCH}$ connection (section 4).

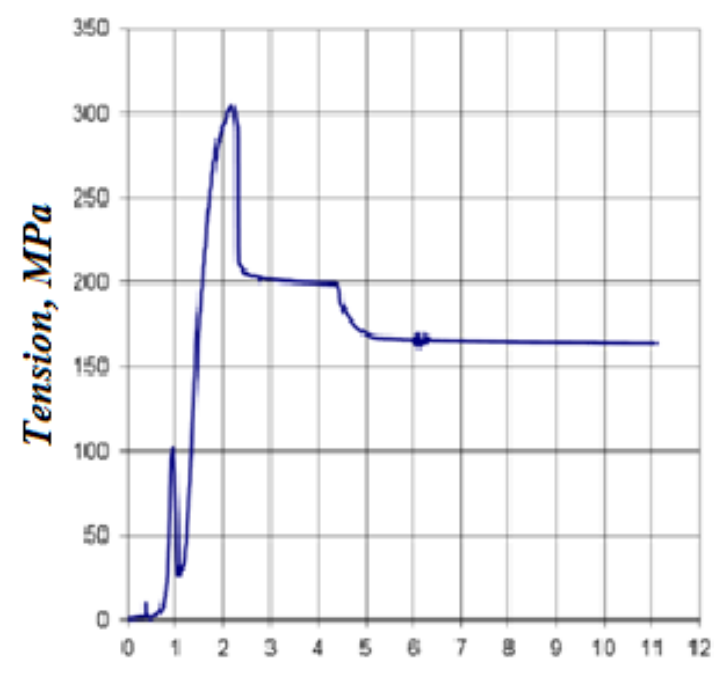

Time, sec

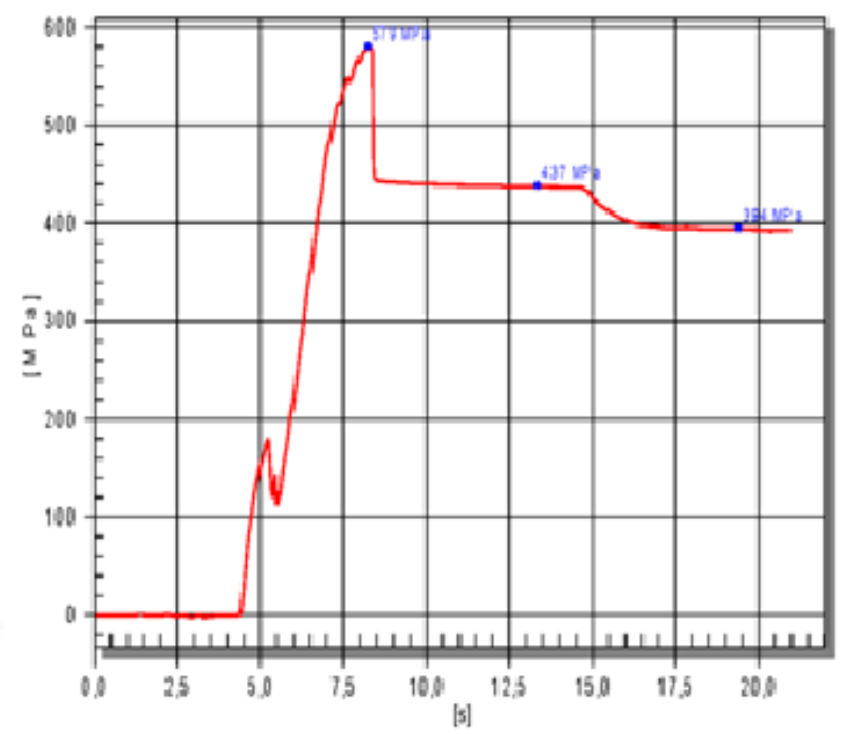

Fig.11. Change in stress in the pin shaft during formation PwCH connections

Determination of the interference force $\left(\mathrm{P}_{\mathrm{H}}\right)$ is carried out according to the formula: 


$$
P_{H}=q_{s} F
$$

where $q_{s}-$ tension of the preload of the pin, MPa,

$F$ - cross-sectional area of the pin shaft, $\mathrm{mm}^{2}$.

The load-bearing capacity of the Pwc joint, in particular the shear resistance, depends on the interference force $(\mathrm{PH})$, which can be found by the formula 1 .

\section{Results and discussion}

Tests to determine the tightness of the pins during the formation of $\mathrm{PwCH}-$ connections were carried out on the plates and on the wedge fixture. The test results indicate that the residual pin tightness characterizes the compression force of the plates and the shear resistance. The tests were carried out on the pins of the batch No. 2 with a diameter of $16 \mathrm{~mm}$ with two lots of crimping heads: with an internal (landing) diameter of 17.0 and $16.65 \mathrm{~mm}$.

The tests showed that the tightness of $16 \mathrm{~mm}$ pins of the $\mathrm{PwCH}$ connection with heads having a seating size of $17.0 \mathrm{~mm}$ varies from 40 to $210 \mathrm{MPa}$, and with heads with a landing diameter of $16.65 \mathrm{~mm}$ - 350-550 MPa.

Based on the results obtained, it was concluded that heads with a landing diameter of $17+0.1 \mathrm{~mm}$ do not ensure the normal operation of the $\mathrm{PwCH}$ connection and should not be used in the manufacture of an experimental batch of gondola wagon hatch covers [12-16].

Breakaway resistance of the crimping head of the $\mathrm{PwCH}$ connection. In accordance with the approved methodology, the tests were carried out on pins with a crimping head. The $\mathrm{PwCH}$ compound was created on a wedge device. After removing the preload and removing the pin with the crimp head, the test for the separation of the crimp head was carried out on a tensile testing machine with a maximum load of $50 \mathrm{kN}$.

Three types of $\mathrm{PwCH}$ compounds were tested:

- with a crimping head with an inner diameter of $16.6 \mathrm{~mm}$,

- with crimp head inner diameter $17.0 \mathrm{~mm}$

- with crimp head with an inner diameter of $16.65 \mathrm{~mm}$.

During the test, the diagram "load - deformation" was recorded until the crimp head was torn off, Fig.12.

The test results indicate that the $\mathrm{PwCH}$ connection with a crimp head with an inner diameter of $16.6 \mathrm{~mm}$ withstands a maximum load of $150 \mathrm{kN}$ until the crimp head comes off. The PwCH connection with a crimping head with an internal diameter of $17.0 \mathrm{~mm}$ can withstand a load of 60 to $80 \mathrm{kN}$. When the $\mathrm{PwCH}$ connection is made of parts with a crimping head with an inner diameter of $16.65 \mathrm{~mm}$, the crimping head is detached at a load of $175 \mathrm{kN}$.

a)

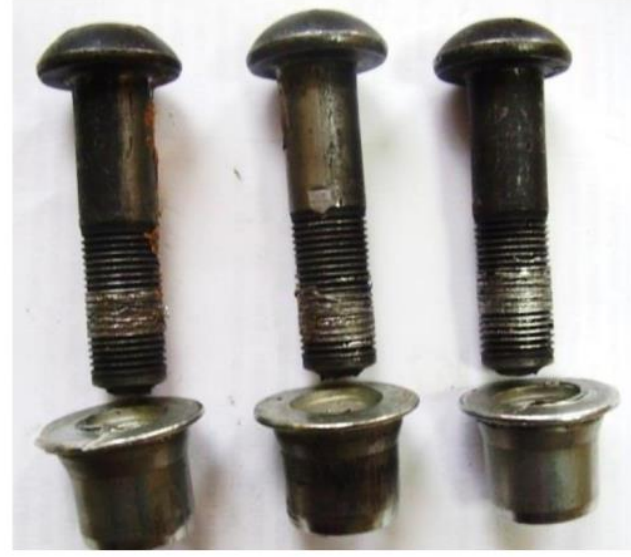

b)

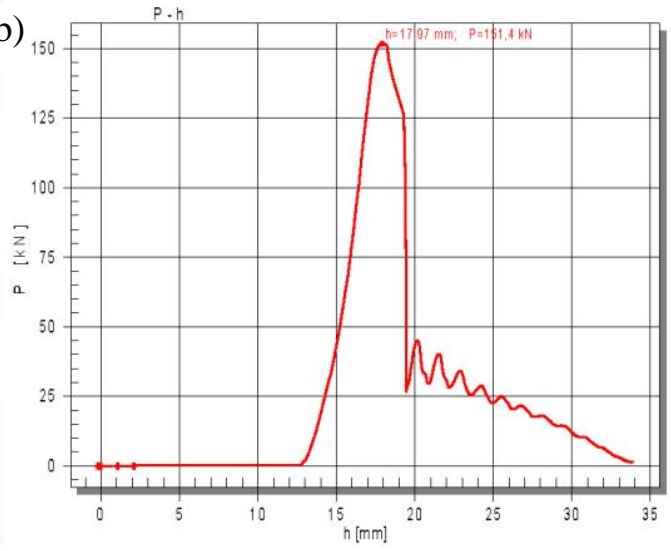

Fig. 12. Crimp head tear test (a), tear load crimp head (b) 
Determination of $\mathrm{PwCH}$ resistance to shock loads. The resistance of the $\mathrm{PwCH}$ connection to shock loads was determined according to a procedure approved in the established manner. The tests were carried out on plates with $\mathrm{PwCH}$ joints, equipped with strain gauges to determine the tightness of the pins and its changes during shock loading (Fig. 13). To create an impact load, a vertical pile driver with an energy reserve of $2 \mathrm{~kJ}$ was used.

An impact load was applied to the end of the pin from the crimp head side. The supporting surface was the surface of the plate. The pin head was in a free state.

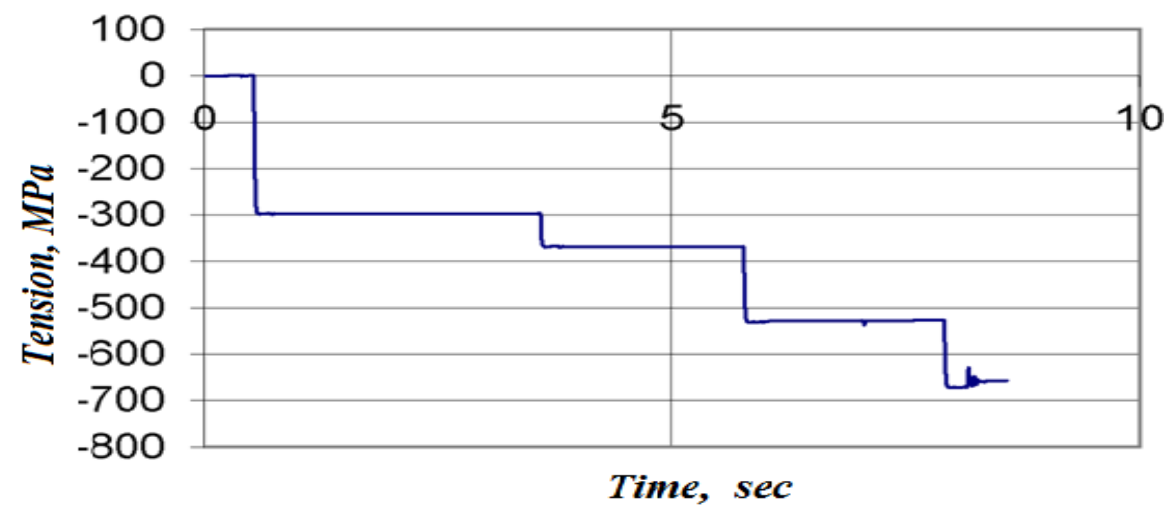

Fig.13. Change in pin interference

We tested PwCH connections:

- with a crimping head with an inner diameter of $16.6 \mathrm{~mm}$;

- with a crimping head with an internal diameter of $17.0 \mathrm{~mm}$;

- with a crimping head with an inner diameter of $16.65 \mathrm{~mm}$.

The tests have shown that unloading from interference and weakening of the $\mathrm{PwCH}$ connection occurs at different impact energies depending on the amount of preload and the dimensions of the details of the $\mathrm{PwCH}$ connection:

- $\mathrm{PwCH}$ connections with a crimping head with an internal diameter of $16.6 \mathrm{~mm}-1.25 \mathrm{~kJ}$ (total with an interference fit of $500 \mathrm{MPa}$ );

- $\mathrm{PwCH}$ connection with a crimping head with an internal diameter of $17.0 \mathrm{~mm}-0.15-0.25 \mathrm{~kJ}$;

- $\mathrm{PwCH}$ connection with a crimping head with an inner diameter of $16.65 \mathrm{~mm}-1.5-2.0 \mathrm{~kJ}$.

\section{Conclusions}

Thus, in terms of resistance to shock loads of the $\mathrm{PwCH}$ connection with a crimping head with an internal diameter of $16.65 \mathrm{~mm}$, it slightly exceeds the results obtained at the $\mathrm{PwCH}$ connection with a crimping head with an internal diameter of $16.6 \mathrm{~mm}$.

1. The use of $\mathrm{PwCH}$ connections with the correct choice of the type of pins and crimp heads, as well as the number of $\mathrm{PwCH}$ connections of individual elements of the body of a freight car made of aluminum alloy, allows for long-term operation of the body without damage to the base metal and joints.

2. For the correct choice of the number of $\mathrm{PwCH}$ connections, it is necessary to determine the bearing capacity of a single connection under various exposure to loads (static, cyclic, shock), taking into account the real working conditions of the connected body units.

3. The proposed samples simulate the working conditions of individual body elements. Based on the results of the testing of model samples, it is possible to determine the bearing capacity of the $\mathrm{PwCH}$ compounds of the selected type and calculate the number of compounds that can withstand standard loads without breaking during the specified service life of the wagon.

4. When testing the PwCH connection "profile (omega large) $+3 \mathrm{~mm}$ sheet" for three-point bending with a distance between the supports of $0.5 \mathrm{~m}$ and cyclic loading in the middle of the span, the limited endurance limit was $50 \mathrm{kN}$ (load) or $34.7 \mathrm{MPa}$ by voltage. The limited endurance limit of "Omega large - sheet with a thickness of $3 \mathrm{~mm}$ " composite samples, depending on the manufacturing technology of $\mathrm{PwCH}$ compounds (tensile force $26.6 \mathrm{kN}$ ) based on 1 million cycles, 
is $41 \mathrm{MPa}$ with an $\mathrm{PwCH}$ connection BobT ail and $55 \mathrm{MPa}$ with an $\mathrm{PwCH}$ connection with detachable shank and gasket under the crimp head.

5. The shear force on the samples without coating, when using the fastener pin MVT-OT16-30L, diameter $16 \mathrm{~mm}$, with a crimping head MBTC-R16BL, a pulling force of $116 \mathrm{kN}$ is $80 \mathrm{kN}$, and coated with primer EF-065 on a polished surface - $32 \mathrm{kN}$. In the future, it is advisable to develop ways to increase shear in the presence of an anti-corrosion coating or electrical insulating linings.

\section{References}

[1] Zaripov R., Gavrilov P. Research opportunities to improve technical and economic performance pf freight wagon through the introduction of lightweight materials in their construction. Journal "Procedia Engineering" Vol. 187, 2017, pp. 22-29.

[2] Шуртаков А. Оптимизация состава и механических свойств сварных и крепежных соединений алюминиевых сплавов для создания кузовов железнолорожных вагонов. (Optimization of the composition and mechanical properties of welded and fasteners of aluminum alloys to create a new generation car body for railroad cars]: dis. on the competition uch. step. cand. tech. sciences. - Moscow, 2017. 193 p. (In Russion)

[3] Hirsch J. Recent development in aluminium for automotive applications J. Hirsch Transactions of Nonferrous Metals Society of China: Volume 24.- Issue 7.- July 2014, pp.1995-2002.

[4] Abovyan T. Formability prediction of aluminum sheet alloys under isothermal forming conditions. T. Abovyan, G. T. Kridli, P. A. Friedman, G. Ayoub// Journal of Manufacturing Processes: Volume 20.- Part 2.- October 2015, pp. 406-413.

[5] GOST 25.502-79 Calculations and strength tests in mechanical engineering. Methods of mechanical testing of metals. Methods of fatigue tests. - Moscow: standardinform, 2005. - 27 p.

[6] Drits A.M Welding aluminum alloy 1565ch [Text]/ a.m. Drits, V. V. Ovchinnikov. - Moscow: mechanical engineering and engineering education, 2014. - № 4. - pp. 6-12.

[7] Gorbunov M., Gerlici J., Kara S., Nozhenko O., Chernyak G., Kravchenko K., Lack T. New principle schemes of freight cars bogies. Manufacturing Technology 18(2), 2018, pp. 233-238.

[8] Harak S. S., Sharma S. C., Harsha S. P., 2014. Structural dynamic analisis of freight railway wagon using finite element method// Materials on 3rd International Conference "Processing and Characterisation" (ICMPC 2014)

[9] Trejo-Escandon J. O., Leyva-Diaz A., Sandoval-Pineda J. M., Tamayo-Meza P. A., Flores-Herrera L. A. Static and Fatigue Analysis of the Front Draft Lugs of a Railroad Tank-Car Using FEM. International Journal of Engineering Trends and Technology (IJETT) - Volume 16 Number 1, 2014.

[10] Wabtec Corporation, Freight Car Draft Arrangements, Wabtec Corporation, USA, 2003.

[11] Płaczek M., Wróbel A., Buchacz A. A concept of technology for freight wagons modernization//Materials of 20th Innovative Manufacturing Engineering and Energy Conference. Series: Materials Science and Engineering 161, 2016.

[12] Janic M. High-speed Rail and Air Passenger Transport: A comparison of the Operational Environmental Performance. Proceedings of the Institution of Mechanical Engineers, Part F: Journal of Rail and Rapid Transit, 217, 2013, 259-269.

[13] Voropai V. Development of a design-experimental methodology for the prediction of reliable exploitation of freight railway cars. Transport problems 2017 Volume 12 Issue 3

[14] Płaczek M., Wróbel A., Buchacz A. A concept of technology for freight wagons modernization 20th Innovative Manufacturing Engineering and Energy Conference, 2016.

[15] EN 12663-2:2010: Railway applications - Structural requirements of railway vehicle bodies Part 2: Freight wagons.

[16] Jönsson P.A., Stichel S., Persson I. New simulation model for freight wagons with UIC link suspension, Vehicle System Dynamics 46, 2008, pp. 695-704. 